\section{How Old are the Angiosperms?}

IN the first of two recently published papers a fossil nut which looks very like some of the modern Icacinaceae is described ("An Early Cretaceous (Hanterivian) Angiosperm Fruit from California", by M. E. J. Chandler and D. I. Axelrod; "How Old are the Angiosperms?" by D. I. Axelrod. Amer. J. Sci., 259, 441; 1961). This tropical family is regarded as moderately advanced, and if the fossil (which is classified with great caution) is rightly placed it fits very nicely with the thesis of the second paper. In this, Axelrod defends his wellknown idea that the flowering plants arose in the 'uplands' during the late Palæozoic (and being upland were very seldom preserved). Here in the uplands they evolved most of their families during the early Mesozoic, and when they appear in force in the Upper Cretaceous this is due to their conquest of the delta habitat rather than to evolution.

Axelrod's arguments had recently been attacked by Scott, Barghoorn and Leopold ("How Old are the Angiosperms?", Amer. J. Sci., 258, A, 284; 1960), and a good deal of the present paper can be crudely summarized thus: lack of evidence can be explained away (and in several different ways); and if certain early fossils supposed to be Angiosperms have not been strictly proved to be Angiosperms, neither have they been strictly proved not to be Angiosperms. To the reviewer it looks as if at least as much thesis has by now been built on the early fossils as they will support, and what is needed is more support; not perhaps by more early fossils but by fuller knowledge of those we have. If, for example, the fossil nut in the first paper was shown by further knowledge to agree with the Icacinaceae and with them exclusively, we would have a very useful basal fact.

\section{Yorkshire Philosophical Society}

The report of the Council of the Yorkshire Philosophical Society for 1960 rightly states that it was an important year for the Society. By a mandate given at a special general meeting in December 1959, an agreement was made with the Corporation of York for it to take over the future maintenance of the Yorkshire Museum, its collections and Gardens. They will be managed by a joint committee, onethird of the members of which will be nominated by the Council of the Society. Founded in 1822, the decision to give the Museum and Gardens to the City after 139 years of an existence entirely supported by members is a historic one and the occasion was marked by appropriate ceremony. It is felt that the community at large will benefit greatly by such a gift, and the Society will be free to develop its separate interests. An unexpected discovery in the excavations in the Garden was an apparently late. fourth-century ditch. It is hoped that further work will shed more light on this last phase of Roman York.

\section{International Business Machines, United Kingdom,} Ltd.

International Business Machines, United Kingdom, Ltd., have announced the foundation of three research fellowships, one in each of the years 1961, 1962 and 1963, tenable at any university or university college in the United Kingdom, under a eontinuing scheme (IBM Research Fellowships. Pp. 4. London: IBM United Kingdom, Ltd., 1961). The fellowships, which will carry a salary of not less than $£ 1.000$ a year, will be in no way restricted as to subject, and will be of sufficient duration to allow research into major problems to be undertaken. The 1961 fellowship has been awarded to the Department of English and General Linguisties at the University of Edinburgh. The facilities of the full range of installed International Business Machine equipment are also to be made available free of charge for approved academic and humanitarian research of a non-profit-making nature. The terms of this Endowed Research Time scheme are set out in a further booklet (Endowed Research Time. Pp. 3. London: IBM United Kingdom, Ltd., 1961).

\section{Research Grants in Radiological Health}

IN view of the rapid expansion which is forecast in the use of nuclear energy, $\mathrm{X}$-rays and other sources of radiation, a greatly expanded programme for research grants in the field of radiological health has been developed by the U.S. Public Health Service. These grants are offered to support research by individuals, universities, hospitals, laboratories and other public or private institutions in the assessment and control of the effects of man-made and natural radiation on the individual. Research proposals should contribute to the determination of the extent and character of the radiation problem as well as the mechanisms by which radiation produces damage. Information and application forms can be obtained from Dr. Paul F. Hahn, chief of the Office of Extramural Grants, Division of Radiological Health, U.S. Public Health Service, Washington 25 , D.C.

\section{American Grants for Nuclear Equipment in Argentina, Brazil and Israel}

The United States is to make available to the International Atomic Energy Agency approximately 80,000 dollars-worth of nuclear equipment to assist in developing the peaceful uses of atomic energy in Argentina, Brazil and Israel. Argentina will receive a grant for a mass spectrometer ion-source to be used in the electromagnetic separation of short-lived radioactive material, and an electron paramagnetic resonance spectrometer to be used in connexion with solid-state physics work being conducted at the Institute of Physies of San Carlos de Barilocho. The grant to Brazil will provide equipment for research in the use of isotopes in agriculture. Israel will receive equipment for one mobile and two stationary monitoring stations as part of its radiological protection programme to provide routine monitoring of the area surrounding the swimming-pool-type research reactor located near Rehovoth, Israel.

\section{Monograph Prizes}

The American Academy of Arts and Sciences is offering three 1,000-dollar prizes, to be awarded annually to the authors of unpublished monographs -one each in the fields of the (1) humanities, (2) social sciences, (3) physical and biological sciences. The final date in 1961 for receipt of manuscripts by the committee on awards is October 2. Details can be obtained from the Committee on Monograph Prizes, American Academy of Arts and Sciences, Little Hall 33, Harvard University, Cambridge 38 . Mass.

NATO Advanced Study Institute Programme, 1962

SHort courses at which scientific topies are discussed at an advanced level may be eligible for 